\title{
Effects of sufentanil on human gastric cancer cell line SGC-7901 in vitro
}

\author{
WEIDONG WU ${ }^{1,2^{*}}$, NINGXIAN WEI ${ }^{1,2^{*}}$, CHUN-NAN JIANG ${ }^{1,2}$, SUYANG CUI ${ }^{3,4}$, JINTAO YUAN ${ }^{1,2}$ \\ 'Danyang People's Hospital of Jiangsu Province, Danyang, Jiangsu, PR China \\ ${ }^{2}$ Danyang Hospital affiliated to Nantong University, Danyang, Jiangsu, PR China \\ ${ }^{3}$ Jiangsu Province Hospital of TCM, Nanjing, Jiangsu, PR China \\ ${ }^{4}$ Affiliated Hospital of Nanjing University of TCM, Nanjing, Jiangsu, PR China \\ *Weidong Wu and Ningxian Wei are the co-first authors
}

\begin{abstract}
Sufentanil is a new kind of opioid analgesic and acts on $\mu$ opioid receptor. In this study, we aim to investigate the effects of sufentanil on gastric cancer cell line SGC-7901, after being exposed to different concentrations of sufentanil. Gastric cancer cells were exposed to sufentanil for a predetermined time at concentrations of $0,0.5,5,50$ and $500 \mathrm{nmol} / \mathrm{l}$, respectively. Cell viability at different time points after exposure to sufentanil was tested by CCK-8 assay. FDA-PI staining was used to observe membrane integrity of gastric cancer SGC7901 cells. The apoptosis of gastric cancer cells was analyzed by Annexin V-FITC/PI Flow Cytometry and the changes of the cell cycle was determined by a detection kit. As a result, cell viability decreased in a dose- and time-dependent manner. Furthermore, with the concentration of sufentanil increased, the proportion of dead and apoptotic SGC-7901 cells increased, and more cells were arrested in G2/M phase. In a word, sufentanil can inhibit the cell viability and induce the apoptosis of gastric cancer SGC-7901 cells in vitro.
\end{abstract}

Key words: sufentanil, gastric cancer cell, cell cycle arrest, apoptosis.

(Centr Eur J Immunol 2014; 39 (3): 299-305)

\section{Introduction}

Sufentanil is a new kind of potent opioid analgesic and acts on $\mu$ opioid receptor. Due to its strong liposolubility and high adherence ratio to plasma protein in human, sufentanil displays its powerful analgesic effects, which is 5-10 times higher than fentanyl and much higher than morphine.

Some researches [1-11] had found that some opioid can partially inhibit the growth of the tumor cells. For instance, morphine inhibited tumor cell proliferation at the concentration of less than $10 \mu \mathrm{M}$ [1] and exogenous morphine can inhibit the growth of human gastric cancer cell line MGC-803 [12]. On the contrary, other studies found that the opioid could promote the survival of tumor cells [13-18]. In a clinically relevant dose, morphine could promote tumor neovascularization in a breast tumor xenograft model in mice, which led to tumor progression [16]. Morphine also displayed the effects that can trigger the proliferation of glioblastoma T98G cell [17]. In addition, as another opioid receptor agonist, remifentanil possesses the capability of increasing cellular respiration of human hepatocytes and inhibiting tumor necrosis factor $\alpha$ (TNF- $\alpha)$ induced mitochondrial dysfunction [18].

However, so far, the underlying exact mechanisms how the opioid affects tumor cells has still not been clear- ly understood. In the present study, as an opioid analgesic, sufentanil was selected to analyze its effects on human gastric cancer cell line SGC-7901 in vitro. After exposure to human gastric cancer cells, sufentanil displayed some characteristics that can inhibit the cell viability and induce the apoptosis of gastric cancer SGC-7901 cells in vitro.

\section{Material and methods}

\section{Chemicals}

Sufentanil was purchased from Yichang Humanwell Pharmaceutical Co., Ltd. (Yichang, Hubei, China). Dulbecco's modified Eagle's medium (DMEM), penicillin, streptomycin sulfate, trypsin, fluorescein diacetate (FDA), propidium iodide (PI) and fetal bovine serum (FBS) were purchased from Sigma-Aldrich Inc. (St. Louis, MO, USA). Cell counting-8 kit (CCK-8), Annexin V-FITC/PI apoptosis detection kit, and Cell cycle and apoptosis analysis kit were obtained from Vazyme Biotech Co., Ltd. (Nanjing, Jiangsu, China). Human gastric cancer cell line SGC-7901 was kindly presented by the Jiangsu Key Laboratory of Molecular Medicine, Medical School of Nanjing University. All reagents were of analytical grade.

Correspondence: Jintao Yuan, Danyang People's Hospital of Jiangsu Province, 2 Xinmin West Road, Danyang, 212300, China,

tel. +8651186523551, fax +8651186553198, e-mail: yjt1020800@sina.com 


\section{Cell culture}

Human gastric cancer cell line SGC-7901 was cultured in an incubator with $5 \% \mathrm{CO}_{2}$ at $37^{\circ} \mathrm{C}$, and DMEM medium was supplemented with $10 \%$ heat-inactivated fetal bovine serum, penicillin $(100 \mathrm{U} / \mathrm{ml})$ and streptomycin sulfate (100 $\mu \mathrm{g} / \mathrm{ml})$. The cells in the logarithmic growth phase were collected and prepared for the study.

\section{Cell viability assay}

After sufentanil exposure, human gastric cancer cell line SGC-7901 was analyzed by Cell Counting Kit-8 (CCK-8) test for evaluating the changes in cell viability. Briefly, cells were put into a 96-well culture plate at a density of $2 \times 10^{4}$ cells/well with $100 \mu \mathrm{l}$ of culture medium. After incubation for $24 \mathrm{~h}$, the cells were divided into four processing time groups, then exposed to different levels of sufentanil at concentrations of $0,0.5,5,50$, and $500 \mathrm{nM}$ respectively. After exposure to sufentanil for $6,12,24,48 \mathrm{~h}$ for different groups respectively in $5 \% \mathrm{CO}_{2}$ at $37^{\circ} \mathrm{C}$, the assay was operated in accordance with instructions of the CCK- 8 kit. Finally, the absorbance was measured at $450 \mathrm{~nm}$ using an automated microplate reader (Bio-Rad, Japan).

\section{FDA and PI staining for morphologic evaluation}

FDA-PI staining can be employed to distinguish viable $\left(\mathrm{FDA}^{+} \mathrm{PI}^{-}\right)$from apoptotic or dead cells $\left(\mathrm{FDA}^{-} \mathrm{PI}^{+}\right)$. Fluorescein diacetate (FDA) can penetrate the cell membrane, then hydrolyzed by nonspecific esterases in viable cells, displaying green fluorescence that is retained in the cyto-

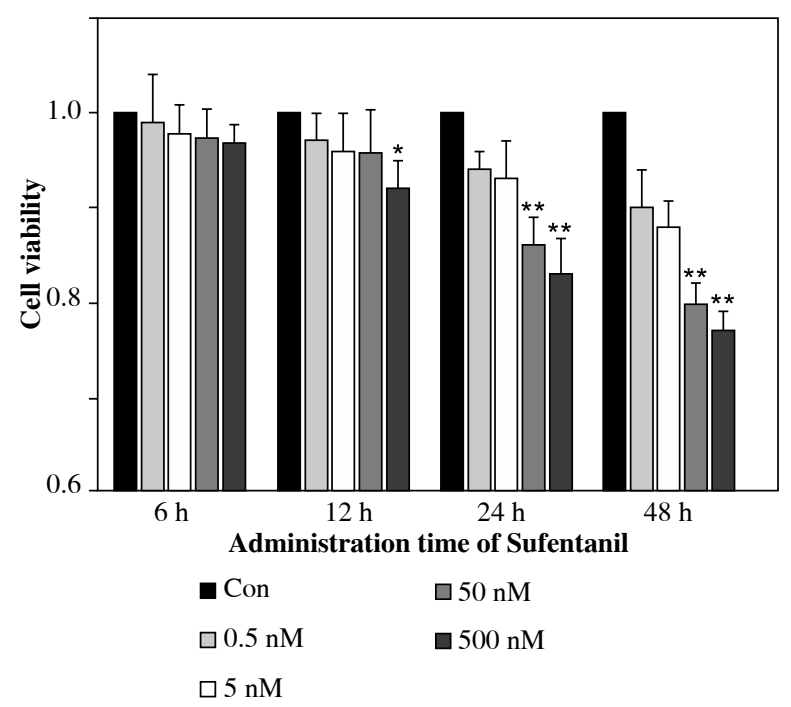

Fig. 1. Effect of different concentrations of sufentanil on cell viability of cultured SGC-7901 gastric cancer cells after being treated for 6 h, 12 h, 24 h and 48 h. Data are shown as mean \pm S.E. $(n=6)$. Asterisk denotes a response that is significantly different from the control $\left(^{*} p<0.05\right.$, $\left.{ }^{* *} p<0.01\right)$ plasm of intact cells. However, if the cells are apoptotic or dead, fluorescence is decreased due to the lack of esterases and the leakage of FDA from the cells for poor membrane integrity. Propidium iodide (PI), a nucleic acid-binding dye, can be excluded from viable cells but possesses the ability to enter dead or dying cells readily for the loss of membrane integrity. In our research, cells were inoculated at a density of $2 \times 10^{5} \mathrm{ml}^{-1}$ into 96 -well plates. After being incubated for $24 \mathrm{~h}$, cells were treated with $0,0.5,5,50,500 \mathrm{nM}$ sufentanil respectively for $24 \mathrm{~h}$, then stained with $5 \mu \mathrm{g} / \mathrm{ml} \mathrm{PI}$ and $4 \mu \mathrm{g}$ / $\mathrm{ml}$ FDA. Finally, the cells were observed using a fluorescent microscope (Nikon, Chiyoda-ku, Tokyo, Japan).

\section{Measurement of apoptosis}

After exposure to sufentanil, apoptotic cells were identified by the Annexin V-FITC Apoptosis Detection Kit according to the manufacturer's instructions. SGC-7901 cells were treated with different concentrations of sufentanil for $24 \mathrm{~h}$, then a FACS calibur flow cytometer (BD, USA) was employed. About $1 \times 10^{6}$ cells for each group were stained with Annexin V-FITC for $30 \mathrm{~min}$ at $4^{\circ} \mathrm{C}$ in the dark, and then with propidium iodide for $10 \mathrm{~min}$ before flow cytometric analysis.

\section{Cell cycle analysis}

Briefly, gastric cancer cells were divided into five groups with about $1 \times 10^{6}$ cells for each, processed with the aforementioned different concentrations of sufentanil for $24 \mathrm{~h}$, then washed twice with ice-cold PBS, treated with trypsin and finally fixed in cold $70 \%$ ethanol for $30 \mathrm{~min}$ at $4^{\circ} \mathrm{C}$. The following operations were carried out in accordance with the manufacturer's instructions of the Cell Cycle and Apoptosis Analysis Kit. Flow cytometry was used for analyzing the treated cells.

\section{Statistical analysis}

Each experiment was performed in sextuplicate and repeated at least three times to ensure the replicability. A separate cell preparation was used for each experiment. The data were expressed as the mean \pm standard error (S.E.). All calculations and statistical analysis were performed using SPSS for windows version 17.0 (SPSS Inc., Chicago, IL, USA) and Origin pro 8.0 software programs (Origin Lab Co., Northampton, MA, USA). One-way analysis of variance (ANOVA) was used to analyze the difference between groups, followed by Dunnett's $t$-test. $P<0.05$ was regarded as statistically significant.

\section{Results}

\section{Cell viability assay}

It could be found that, at different time points after treatment with sufentanil, the cell viability of all groups de- 
creased as the concentration of sufentanil elevated (Fig. 1). For the 12 h-treated group, cell viability significantly decreased as the concentration of sufentanil reached $500 \mathrm{nM}$. When the processing time was $24 \mathrm{~h}$ or $48 \mathrm{~h}$, compared with the control group, the differences in cell viability are extreme- ly significant when the concentration of sufentanil reached $50 \mathrm{nM}$ or above. The results indicated that the growth and proliferation of cancer cells was inhibited after being exposed to sufentanil. Especially, for SGC-7901 cells, the lowest effective concentration of sufentanil may be only $50 \mathrm{nmol} / \mathrm{l}$.
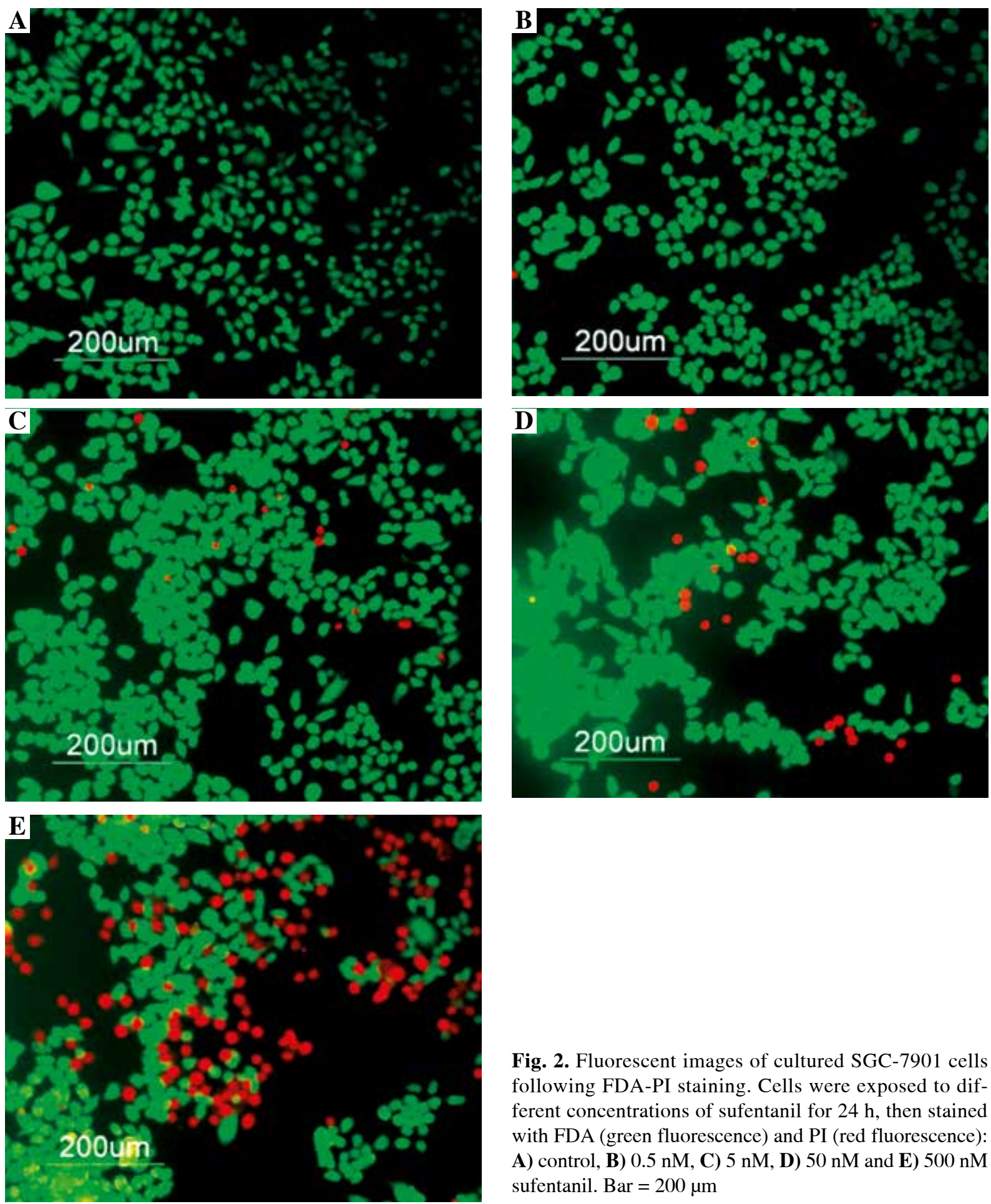

Fig. 2. Fluorescent images of cultured SGC-7901 cells following FDA-PI staining. Cells were exposed to different concentrations of sufentanil for $24 \mathrm{~h}$, then stained with FDA (green fluorescence) and PI (red fluorescence): A) control, B) $0.5 \mathrm{nM}$, C) $5 \mathrm{nM}$, D) $50 \mathrm{nM}$ and E) $500 \mathrm{nM}$ sufentanil. Bar $=200 \mu \mathrm{m}$ 
A

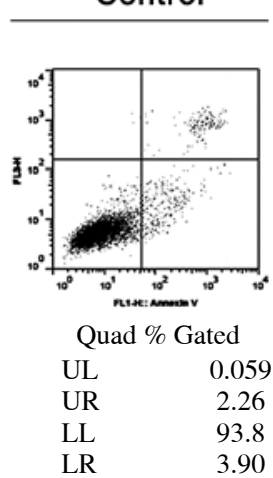

Treated with sufentanil

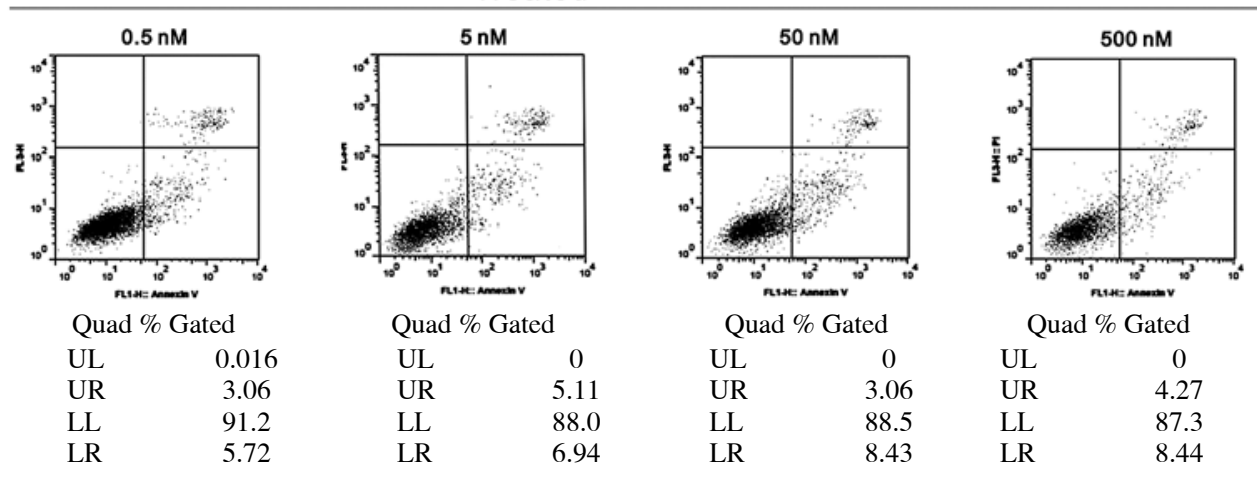

B

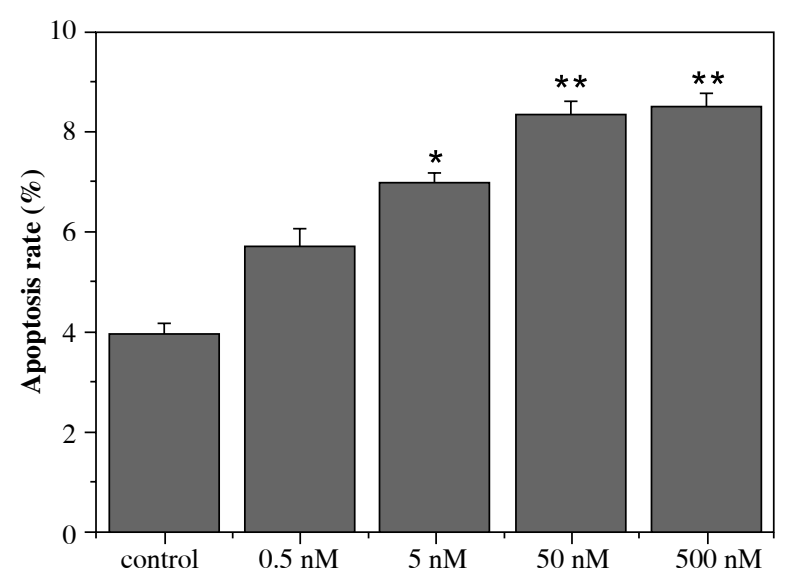

Fig. 3. A) Flow cytometry dot plots showing the binding of Annexin V-FITC (FL-1) and PI uptake (FL-3) of SGC-7901 cells treated with different concentrations of sufentanil for $24 \mathrm{~h}$, followed by percentages of four quadrants respectively below. B) Apoptosis rates of SGC-7901 gastric cancer cells after being treated with different concentrations of sufentanil for $24 \mathrm{~h}$. Data are shown as mean \pm S.E. $(n=3)$. Asterisk denotes a response that is significantly different from the control $\left({ }^{*} p<0.05,{ }^{* *} p<0.01\right)$

\section{FDA and PI staining}

As the concentration of sufentanil increased, the proportion of dead cells that display red fluorescence increased, however viable cells that show green fluorescence gradually reduced (Fig. 2), which could be clearly observed by fluorescence microscopy. These findings suggested that the membrane integrity in part of gastric cancer cells had been destroyed when exposed to sufentanil, and the number of dead cells displayed a dose-dependent effect.

\section{The analysis of apoptosis}

To further study the possible inducing apoptosis effect of sufentanil on SGC-7901 gastric cancer cells, cells were stained with Annexin V-FITC and PI, and subsequently analyzed by flow cytometry. The dual parameter fluorescent dot plots showed that the viable cells (Annexin $\mathrm{V}^{-} / \mathrm{PI}^{-}$) were in the lower left quadrant, the apoptotic cells were in the lower right quadrant (Annexin $\mathrm{V}^{+} / \mathrm{PI}^{-}$). As indicated in Fig. 3A and 3B, with the concentration of sufentanil elevated, the percentages of apoptotic cells increased. When treated with $50 \mathrm{nmo-}$ 1/1 sufentanil or above, compared with the control group, the percentages of apoptotic cells were significantly higher $(p<0.01)$. Obviously, these results indicated that sufentanil could induce apoptosis in gastric cancer SGC-7901 cells.

\section{Effect of sufentanil on cell cycle}

Flow cytometry was used to determine whether the inhibitory effects of sufentanil on the proliferation of SGC7901 cells is mediated, at least in part, through affecting cell cycle progression. As indicated in Fig. 4A, the green peak represented the cells in G1 phase, the yellow peak illustrated the cells in $\mathrm{S}$ phase and the blue peak displayed the cells in G2 phase. When treated with sufentanil at the concentration of $5 \mathrm{nM}$ or above, the percentages of SGC7901 cells in S phase and G2 phase were significantly different from the control (Fig. 4B). These findings indicated 
A

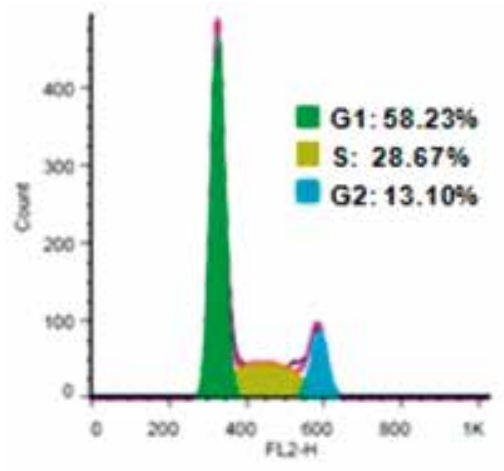

Control

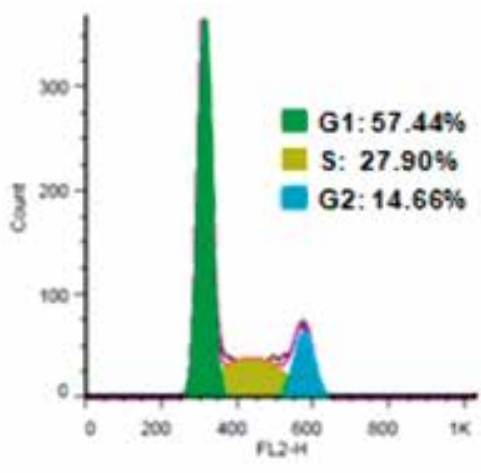

$0.5 \mathrm{nM}$

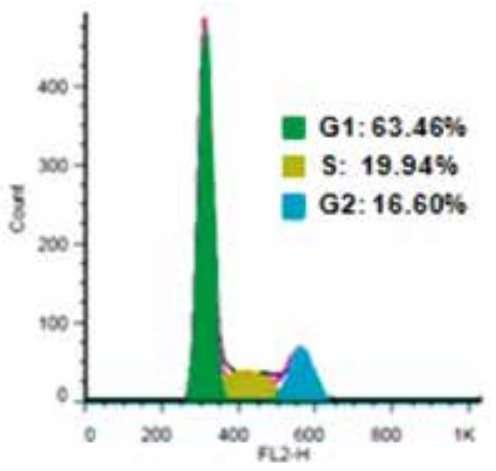

$5 \mathrm{nM}$

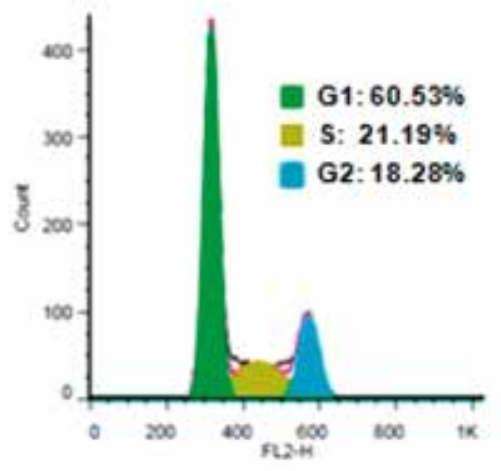

$50 \mathrm{nM}$

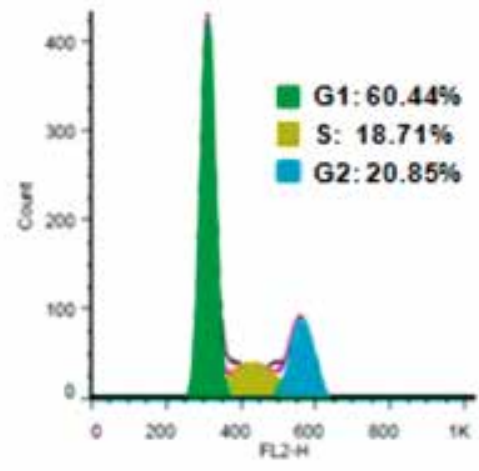

$500 \mathrm{nM}$

B

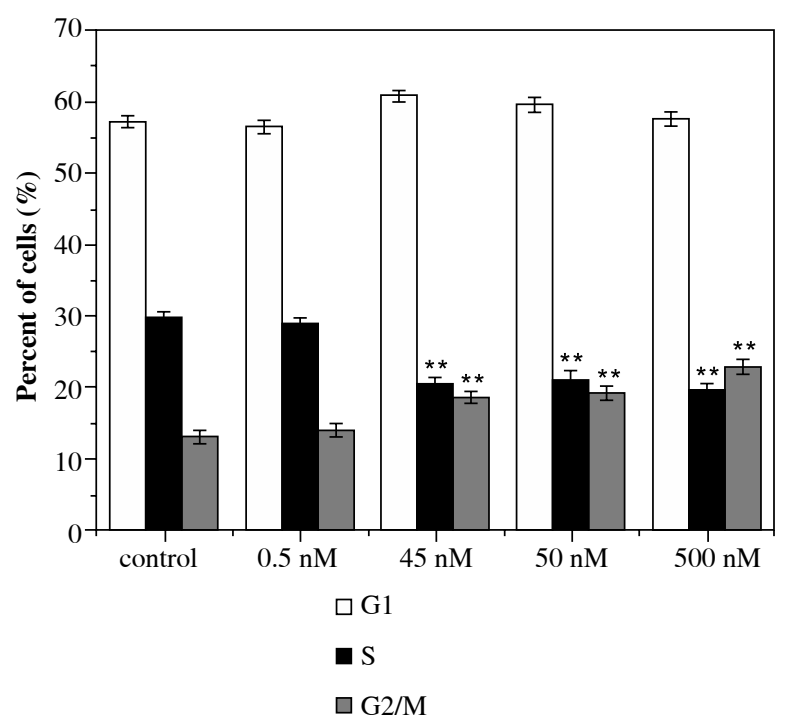

Fig. 4. A) Cell cycle analysis of SGC-7901 cells treated with different concentrations of sufentanil for $24 \mathrm{~h}$. Phases of G1, S and G2 are displayed by three different colors in each chart. B) Percents of SGC-7901 gastric cancer cells in G1, $\mathrm{S}$ and $\mathrm{G} 2$ phase respectively after being treated with different concentrations of sufentanil for $24 \mathrm{~h}$. Data are shown as mean \pm S.E. $(n=3)$. Asterisk denotes a response that is significantly different from the control $\left(" p<0.05,{ }^{* *} p<0.01\right)$ 
that sufentanil could lead to cell cycle arrest at the G2/M phase, suggesting that sufentanil may inhibit cell proliferation through controlling the G2/M checkpoint and inducing a specific block in cell cycle progression.

\section{Discussion}

As a potent analgesic which is widely used in the clinical management of pain, sufentanil is much better than morphine and fentanyl in the analgesic effect, although all these three analgesics play a role through $\mu$ opioid receptors. In recent years, the inhibitory effects of opioid analgesics on the tumor cell growth have been increasingly reported. However, the underlying specific mechanisms wherein are still unknown.

In the present study, through FDA and PI staining and the assay of CCK-8, some facts could be found that with the increasing of the concentration of sufentanil, cell viability declined obviously. Many studies have indicated that morphine, also known as an opioid analgesic, may down-regulate the development and spread of tumor cells. It has been found that morphine inhibited the growth of liver cancer cells in mice [19]. Moreover, morphine has been demonstrated to decrease the development of human breast cancer cells in vitro [6]. So far, the complexity of opioid-tumor cells interactions has been found in many studies, but how they influence the growth of cancer cells is far from being clearly understood.

Apoptosis is an active intracellular programmed death process that is caused by physiological and pathological changes to remove redundant and damaged cells. In our research, gastric cancer SGC-7901 cells were arrested in $\mathrm{G} 2 / \mathrm{M}$ phase increasingly and showed more apoptotic characteristics with the increase of the concentration of sufentanil. In the process of apoptosis, the key point may be the triggering of caspase cascade [20]. For instance, caspase 3 is an well-known main executor of apoptosis and can lead to morphological changes of cells, such as fragmentations of chromosomal DNA and nucleus and the forming of many apoptotic bodies [21]. In addition, NF$\kappa \mathrm{B}$ is a specific nuclear transcription factor that plays an important role in regulation of many genes which closely related to apoptosis and tumorigenesis [22]. A large number of researches suggested that inhibition of NF- $\kappa B$ can suppress the growth of cancer cells [23]. It has been reported that the anticancer effects of opioid analgesic might be mediated through the suppression of NF-кB [24]. Therefore, we believe that the triggering of caspase cascade and inhibition of NF- $\kappa \mathrm{B}$ may be involved in the process of the inhibitory effects on tumor cells growth from sufentanil. However, the specific mechanism remains to be explored in future studies.

In conclusion, sufentanil, one of the potent opioid analgesics, can inhibit the cell viability and induce apoptotic effects when directly touched with gastric cancer SGC-
7901 cells in vitro. Further studies will be needed to explore the exact underlying mechanisms.

\section{Acknowledgements}

The work was supported by the Zhenjiang Social Development Fund of China (FZ2011002) and Danyang Social Development Special Project Fund (DK201109). We sincerely express great gratitude to Jiang $\mathrm{Wu}$ for providing gastric cancer SGC-7901 cells. The authors also wish to thank Lihui Wang, Wenwen Guo and Chaowen Shi for their help in the experiments.

Authors declare no conflict of interest.

\section{References}

1. Tegeder I, Grosch S, Schmidtko A, et al. (2003): G protein-independent $\mathrm{G} 1$ cell cycle block and apoptosis with morphine in adenocarcinoma cells: involvement of p53 phosphorylation. Cancer Res 63: 1846-1852.

2. Maneckjee R, Biswas R, Vonderhaar BK (1990): Binding of opioids to human MCF-7 breast cancer cells and their effects on growth. Cancer Res 50: 2234-2238.

3. Yeager MP, Colacchio TA (1991): Effect of morphine on growth of metastatic colon cancer in vivo. Arch Surg 126: 454-456.

4. Page GG, Ben-Eliyahu S, Yirmiya R, et al. (1993): Morphine attenuates surgery-induced enhancement of metastatic colonization in rats. Pain 54: 21-28.

5. Sueoka N, Sueoka E, Okabe S, et al. (1996): Anti-cancer effects of morphine through inhibition of tumour necrosis factor-alpha release and mRNA expression. Carcinogenesis 17: 2337-2341.

6. Hatzoglou A, Bakogeorgou E, Castanas E (1996): The antiproliferative effect of opioid receptor agonists on the T47D human breast cancer cell line, is partially mediated through opioid receptors. Eur J Pharmacol 296: 199-207.

7. Sueoka E, Sueoka N, Kai Y, et al. (1998): Anticancer activity of morphine and its synthetic derivative, KT-90, mediated through apoptosis and inhibition of NF-kappaB activation. Biochem Biophys Res Commun 252: 566-570.

8. Rasmussen M, Zhu W, Tonnesen J, et al. (2002): Effects of morphine on tumour growth. Neuro Endocrinol Lett 23: 193198.

9. Fichna J, Janecka A (2004): Opioid peptides in cancer. Cancer Metastasis Rev 23: 351-366.

10. Tegeder I, Geisslinger G (2004): Opioids as modulators of cell death and survival--unraveling mechanisms and revealing new indications. Pharmacol Rev 56: 351-369.

11. Chen YL, Law PY, Loh HH (2008): The other side of the opioid story: modulation of cell growth and survival signaling. Curr Med Chem 15: 772-778.

12. Qin Y, Chen J, Li L, et al. (2012): Exogenous morphine inhibits human gastric cancer MGC-803 cell growth by cell cycle arrest and apoptosis induction. Asian Pac J Cancer Prev 13: 1377-1382. 
13. Simon RH, Arbo TE (1986): Morphine increases metastatic tumor growth. Brain Res Bull 16: 363-367.

14. Moon TD (1988): The effect of opiates upon prostatic carcinoma cell growth. Biochem Biophys Res Commun 153: 722727.

15. Ishikawa M, Tanno K, Kamo A, et al. (1993): Enhancement of tumor growth by morphine and its possible mechanism in mice. Biol Pharm Bull 16: 762-766.

16. Gupta K, Kshirsagar S, Chang L, et al. (2002): Morphine stimulates angiogenesis by activating proangiogenic and survival-promoting signaling and promotes breast tumor growth. Cancer Res 62: 4491-4498.

17. Lazarczyk M, Matyja E, Lipkowski AW (2010): A comparative study of morphine stimulation and biphalin inhibition of human glioblastoma T98G cell proliferation in vitro. Peptides 31: 1606-1612.

18. Djafarzadeh S, Vuda M, Takala J, et al. (2012): Effect of remifentanil on mitochondrial oxygen consumption of cultured human hepatocytes. PloS one 7: e45195.

19. Payabvash S, Beheshtian A, Salmasi AH, et al. (2006): Chronic morphine treatment induces oxidant and apoptotic damage in the mice liver. Life Sci 79: 972-980.

20. Yang Y, Yu X (2003): Regulation of apoptosis: the ubiquitous way. FASEB J 17: 790-799.

21. D'Amelio M, Cavallucci V, Cecconi F (2010): Neuronal caspase-3 signaling: not only cell death. Cell Death Differ 17: 1104-1114.

22. Carbone C, Melisi D (2012): NF-kappaB as a target for pancreatic cancer therapy. Expert Opin Ther Tar 16 Suppl 2: S110.

23. Khan NI, Cisterne A, Baraz R, et al. (2012): Para-NO-aspirin inhibits NF-kappaB and induces apoptosis in B-cell progenitor acute lymphoblastic leukemia. Exp Hematol 40: 207-215 e1.

24. Yin D, Woodruff M, Zhang Y, et al. (2006): Morphine promotes Jurkat cell apoptosis through pro-apoptotic FADD/P53 and anti-apoptotic PI3K/Akt/NF-kappaB pathways. J Neuroimmunol 174: 101-107. 